\title{
Invisible Play and Invisible Game: Video Game Testers or the Unsung Heroes of Knowledge Working
}

\author{
Marco Briziarelli
}

\author{
University of New Mexico, Department of Communication and Journalism, Albuquerque, \\ mbriziarelli@unm.edu
}

\begin{abstract}
In this paper, I examine video game testing as a lens through which exploring broader aspects of digital economy such as the intersection of different kind productive practices-working, labouring, playing and gaming-as well as the tendency to conceal the labour associated with them. Drawing on Lund's (2014) distinction between the creative aspects of "work-playing" and the constraining/instrumental aspects of "game-labouring", I claim that video game testing is buried under several layers of invisibility. Ideologically, the "playful", "carnivalesque", quasi-subversive facets of this job are rejected because of their resistance to be easily subsumed by the logic of capitalism. Practically, a fetishist process of hiding human relations behind relations among things (elements in the video game environment) reaches its paradoxical apex in the quality assurance task of this profession: the more the game tester succeeds in debugging games higher is the fetishization of his/her activity.
\end{abstract}

Keywords: Video game testing, Work, Labour, Play, Game, Knowledge Work, Fetishism

Contemporary capitalism is defined by the growing prominence of information and communication as well as the condition of the worker becoming increasingly involved in the tasks of handling, distributing and creating knowledge (Castells 2000). These so called knowledge workers (Mosco and McKercher 2007) operate in a liminal space in between working-time and lifetime, production and reproduction (Morini and Fumagalli 2010). As a result of such interstitiality and the increasing significance of "immaterial labour" (Lazzarato 1996), their productive activities often become almost invisible.

Thus, in a context in which digital labour passes frequently undetected, the present paper considers how video game testing comes to be concealed under a twofold layer of invisibility associated to distinct-but-united productive aspects of this profession: a predominantly ideological layer associated with "play-working", and a predominantly practical one associated with "game-labouring". Drawing on Lund's (2014) distinction between the creative aspects of former and the constraining aspects of the latter, I claim that video game testing exemplifies a much broader condition determined by the current mode of production and the tensions that inhabit it.

In fact, in contemporary information/knowledge driven capitalist scenario video game testing stands almost as an archetype of the dangers and delights of knowledge work. That is because the idea of playing games as a job expresses the aspiration of an utopic and rebellious labour theory of value based on leisure activities, which frictions with waged labour in capitalist society or the seemingly inescapable reality that leads to the necessary acceptance of exploitative or unjust labouring conditions. Concretely, based on an study of internet fora and blogs concerned with video game testing, such a remarkable tension of "play-working" and "game-labouring" materializes in distinctive aspects of this profession: video game testing appears simultaneously to be a "dream job", the professional aspiration of many young video gamers as well as to be characterized by "tedious tasks", "poor compensation", "lacks of respects", "harsh working conditions" and finally "poor job security" (Thang 2012).

On the one hand, if "play-working" traits are present in many knowledge jobs, in this particular one seem to be so preponderant to the point they could subversively exceed capitalism reproductive ideologies. Instead, those utopic aspects become completely invisible, concealed behind a futile and infantile framing of entertainment and the rationalizing force of game-labouring. On the other, from the perspective of game-labouring, the main "quality as- 
surance" task of a video game tester is, conceptually wise, a negative one, as it mainly entails the objective of "debugging" the defects of a given game (Sloper 2011). Thus her/his labour process appears as invisible in the finished product as it becomes symbolically annihilated by the flawlessness (or buglessness) attribute of video games. Consequently, as in the Marxian (1867) commodity fetishism, relations among workers appear as relations among video game elements.

In order to develop my argument, I first provide an account of the cultural practices of video game testing by discussing my observation of Internet for a and blogs dedicated to the topic. I then draw on Lund's categories of play-working and game-labouring to describe how concretely video game testing labour looses visibility. Finally, I contextualize the conditions of those particular producers within the more general framework of information capitalism and knowledge working and the specific tendency of this mode of production to abstract labour from digital products.

\section{1. "I Want to Become a Video Game Tester": Lights and Shadows of a "Dream" Job}

In this section of the paper, I provide an account of the practices and perceptions gravitating around video game testing based on the exiguous existing literature as well as the observation of two texts: a blog that deals with several aspects of this profession, gameindustrycareerguide.com; and a specific section of the internet forum Gamedev.net, "Coding Horrors", where many users interested in video-game testing are active.

Let us start with a brief description of this profession. Simply stated, the work of a video game tester mainly concerns the task of quality assurance of video games, which entails findings defects by testing the limits (or "breaking") of a given product. According to Croce (2007) there are three main tasks involved in testing: bug testing, which implies looking for general glitches in the program and carefully retracing the steps to allow a systematic location of the bug; configuration testing, which implies making sure the game works across all platforms (e.g. PlayStation, Xbox, PC); and game play testing, which entails evaluating the playability and enjoy-ability of the game.

In his blog, game designer and video game tester Jason Bay (2013) claims that QA functions in this job mostly requires dealing with different kinds of bugs. He classifies "A" bugs as highly compromising defects causing the game to crash or not be enjoyable, "B" bugs as secondary problems that can ruin the experience of playing, and finally " $C$ " and " $D$ " bugs as minor defects that can be frequently considered negligible. Schultz, Bryant, Langdell (2011) claim that the debugging goes well beyond the identification of bugs. Once a bug is identified it needs first to be amplified in its defectiveness in order to maximize its fixability. Then, it needs to be reported by systematic note booking and proficient communication, so that game designers can easily identify the problem. Finally, once the bug has been presumably fixed, game testers must verify its absence.

Taylor and Parish (2007) maintain that video game testing "is generally considered to be an entry-level position in the game industry" (192). Most companies do not require a college degree for this occupation and consider game testing to be a "non-exempt" position, which implies a modest hourly salary, being part-time as well as being temporary employed. In fact, video game testing possibly provides the lowest salary in the game industry, with a hourly pay ranging from 8 to 14 dollars and a yearly pay raging from 16.000 to 35.000 dollars (gameindustrycareerguide.com). Moreover, only few larger companies offer to pay for health, dental and vision benefits.

Nonetheless, interestingly enough, the objectively precarious, poorly paid conditions and the exploitative potential of temporary employment conflicts with a diffused perception of this profession to be a "dream job." According to Croce (2007), "for someone who likes videogames the position of video games tester is a dream job [...] you may be thinking: what's the catch? There is no catch. Game testers literally get paid for doing what they love" (74). Bay (gameindustrycareerguide.com, November 29, 2013) confirms the same perception by claim- 
ing: "Of all the jobs in the game industry, I get the most questions about how to become a video game tester".

Indeed, based on Jason Bay's blog, the profession seems to especially attract young people who love playing games and would like to keep doing it as professionals, without the encumbrance of pursuing a higher education degree. Hence, Jacab asks if "high school diploma is enough" (gameindustrycareerguide.com, September 15, 2014). Similarly, Tristan asks if "a college degree is really indispensable to become a professional tester" (gameindustrycareerguide.com, November 29, 2013).

Moreover, videogame testing entails a vocational attitude, for instance Samin (gameindustrycareerguide.com, May 28, 2014) states "I am born to play games [...] I don't care about how much they paid am happy with small amount because that way i can do what I love." Along the same lines, Tai declares "I play now for fun from 8 to 18 hours a day, if not more sometimes I would love to be a tester reporter and get paid to play as you put it." (gameindustrycareerguide.com, August 5, 2014). Eric reiterates the same idea "I want to do something with video games I LOVE video games" (gameindustrycareerguide.com, July 6, 2014). Finally, particularly telling is AprilMitchell asking "My question to you is how can I make a living doing this, I spend so much time and dedication playing games, I feel I should get paid! (gameindustrycareerguide.com, August 21, 2014).

Users such as Jackie also provides more insights about the specific kind of intellectual gratification related to the idea of being capable of "breaking the game":

I recently got to "play test" a game for the first time. It was at an anime convention and they had a demo for it up and running. I found the game itself kind of slow and a little boring but when I clicked on the trees they would either disappear or, if they were dead, flicker back to life. I thought it was so cool that I immediately started looking for more bugs that the creator had missed (gameindustrycareerguide.com, August 5, 2014).

Similarly Slooshgaloosh confirms that game testing is not just about playing but also critically assessing the quality of a conceptual construct: "I personally love breaking games and finding bugs. I just love to find those bugs that the developers/programmers didn't think of being possible or consider happening" (gameindustrycareerguide.com, September 29, 2014).

The intellectual involvement of testers is also exemplified by the popular practice of "modding" (Levy and Noval 2009, 5). By scrutinizing and "breaking" the game, testers can modify the original game code through "partial conversions"-superficial changes such as new character skins, altered weapons-and through "total conversions"-involving creating an entirely new game. While those ideas can be picked by game designers and incorporated in the game, most of the times appear as unnoticed skills. As Sloper (2011) notices "Despite the fundamental task of video game testing, unfortunately - you don't get to interact with developers and producers as much."

As a result, "modding" remains confined as a "show-off" performance for restricted audiences such as the one gravitating around websites such as Modddb.com and Gamedev.com, especially in its section "Coding Horrors." One of the typical profiles of Gamedev.net users active in "Coding Horrors" consists of professional videogame testers with experience programming who share their findings. The predominant rhetoric of those conversations appears as a kind of Derridean deconstructionism that applies its critical inquiry to all possible codes. For instance, user Fasctcall22 posted about the presence of bugs in the very Gamedev.com, the website hosting his message, "This chat, apparently, is a gigantic coding horror" (2014, September 30$)$.

However, despite the diffused enthusiasm, the owner of the blog gameindustrycarrerbuilder.com Jason Bay consistently stresses the distance from perception and reality of this work, which is not always entertaining as it seems, because:

You don't get to just play the game, you have to search for bugs and write a report for each bug you find. Sometimes you could write 20 or more reports each day. Then when the dev. team fixes the bug, you have to go into the game to make sure it's really fixed, which can take a while" (gameindustrycareerguide.com, May 28, 2014). 
He also constantly remarks how video game testing should be considered as a temporary job for students, which would be eventually replaced by "better jobs" such as game designing and programming. Bay claims that many studios treat their QA department as second-class citizens-and pay them accordingly. Furthermore, because of cyclical nature of the game industry, in times of crisis this profession is particularly affected, thus making this job even more unstable and precarious.

In this sense, the already mentioned section of Gamedev "Coding horrors" is also used to ventilate the frustrations implied by game testing. Users complain about the invisibility and the little credit to their function. They seem to acknowledge that their references can only be like "inside jokes" of a community sharing debugging accomplishments. In one of the most popular threads of the forum, "The Wackiest Bug" (Silk-thedgehog 2013, August 9), a typical post shows pictures or videos of glitches. Particularly exemplary is the posted video "GameGlitches: Angry Video Game Nerd" (L.Spiro 2014, July 13), which is my view symptomatic of a tendency to consider game testing as an unproductive hobby for "nerds" rather than a job to earn a living.

Concluding this section, videogame testing appears as a job both desired for the seemingly utopic opportunity to transform playing into "a making a living" and obscured by the lack of consideration/recognition, precariousness, poor pay. In the next section I draw from the political economic framework of Lund (2014) in order closely examine those layers of invisibility:

\section{Competing Theories of Value: Play-Working and Game-Labouring}

Working with the assumption that media practices simultaneously intersect power, labour, value creation and the shaping of subjectivities (see e.g. Arvidsson and Colleoni 2012; Fuchs 2010; Terranova 2013), I build here on Lund's (2014) categories of play-working and gamelabouring in order to provide an account of how fundamental aspects of video game testing labour process can loose the justified prominence. While Lund does not talk directly about this profession, he provides a perspective that in my view synthetizes video game testing's dialectics of emancipatory playful creation and monetizable strategic and formalist attitude of game-labouring.

In his effort to make sense of the distinction between work and labour, Lund cites Fuchs and Sevignani's (2013) inquiry on how Marx and Engels understand human practical activity in binary ways. On the one hand, they define "labour" as "a necessarily alienated form of work, in which humans do not control and own the means and results of production (p.240). On the other, they distinguish labour from "work" as a much more general concept common to all societies. It is a process in which "humans in social relations make use of technologies in order to transform nature, culture and society in such a way that goods and services are created that satisfy human needs" (240).

Both Lund and Fuchs and Sevignani draw on Marx's (1867) reflections in Capital and the distinction between "Labour which creates use-values and is qualitatively determined is called 'work' as opposed to 'labour'; labour which creates value and is only measured quantitatively is called 'labour', as opposed to 'work'" (138). Through "work" human intentions become bound to its product as "use-value" and in such a product people see and recognize themselves. Conversely, "labour" causes multiple kinds of alienation to the workers, thus disrupting the moment of genuine creative activity intrinsic in the experience of "working" and replacing it with the mediation of profit interests and abstractions such as "exchange value."

Thus, to summarize, work is simultaneously a necessary activity for the survival of human beings in a scarce environment and a means for their creative self-expression. By contrast, labour is a social necessity determined by a historic specific political economic regimecapitalism - that entails an abstraction from the genuine use-value of the product of work, alienation and possible exploitation. In this sense, trying to understand an economy that constantly welds together production and entertainment, Lund points out to the parallel concep- 
tual distance between "work" and "labour", and "play" and "game", as well as parallel affinities between "work" and "play" and "labour" and "game".

Lund distinguishes between the open-endedness of playing and the confined challenged of games, the informal character of the former and formal strategic approach of the latter. While gaming is organized, play is capricious in its behaviour and does not follow rules in an explicit and uniform way (Asplund 1987). Correspondingly, play and work are creative and their objectives-such as entertainment, expressive meanings-are qualitatively measured. Contrariwise, game and labour operate in a formal and abstract framework that establishes quantitative relations-such as scoring or exchange value-among the people involved in the activity.

Therefore, play and working are more focused on enjoying the experience while game and labouring tend to measure the performance. Lund (2014) claims that whereas people indeed have a natural need to play and also express themselves in "objective" ways through creative work, game and labouring appear as historic specific categories especially developed in a capitalist context. In fact, in such a scenario, gaming has absorbed the instrumental logic that regulates the political economic management of gains and loss, the calculation of risks and profits.

\section{Play-Working and Game-Labouring}

In the contest of digital media, the four categories "working", "labouring", "play", and "labouring" intersect each other and define a province in which production and consumption, free expression and exploitation meet together. For instance, Barbrook and Cameron (1996) provide a study of how high tech networking technologies has created a vision of the world in which all four dimensions are synthetized in the so called California ideology, a mix of high tech hypsterism and conservatory principles.

In the case of video game testing, for Kampmann (2003) the game industry draws more on the game-labouring side because a digital computer is a discrete state machine that does not allow the space and time for the free casual exploration of playing. Instead, computers bear, in their very design, a strong resemblance to formalized game systems, with rules for discrete sequential operations. Similarly, Juul (2005) points out that the gaming side of video game socializes us to be effective, productive citizens who can administer scarce resources such as capital.

However, the enthusiasm and the genuine recreational aspect of "playing" a video game is never completely eliminated both in the original motivation to test- play a videogame and to modify it. Thus, rational/formal aspect of gaming fuse together with creative work and genuine entertainment. Therefore, in the practices of video game testing, the four dimensions are intermeshed together in indissoluble way.

As Lund (2014) claims, there is a fine line between playing, gaming, working and labouring in the concrete practices of knowledge work. However, despite the complex ways in which those fours dimensions interact with each other, in this paper, I concentrate on the two main binomials of play-working and game-labouring, thus ordering them along the axis constituted by arguably the most spectacular ambivalences of contemporary capitalism and knowledge work: emancipation and exploitation, self-expression and alienation, use value and exchange value, free territory and rule bounded environment.

Therefore, without neglecting the complex web of those relations, I here focus on those tensions in order to accomplish two linked objectives: first, to identify the main forces that create tensions in the practice of video game testing; second to show how the interaction of those forces creates layers of invisibility that tend to practically and symbolically annihilate important aspects of this profession.

\section{Invisible Play-Working}

There are two main aspects that in videogame testing are related to the play-working dimension. First of all, the de facto rebellious labour theory of value of "playing for living" that aspires to create its own means of subsistence by what is perceived as play and enjoyment of 
video games. This is I think is a very interesting aspect of video game testing because shows one of the deep ideological contradictions of post-Fordism: the hybridization of the classic "protestant ethic" that characterizes liberalism (Weber 2009) with the entertainment oriented characteristic of informational capitalism synthetized by the popular expression "work hard and play hard."

While such an update of the Weberian "spirit of capitalism" seems very compatible with a consumption-oriented economy because it implies a seriousness of working that justifies in turn high levels of consumption, the two aspects do not necessarily always work together. For instance, as in the case of video game testing, when those two terms become logically inverted-i.e. "play hard and work hard"- the relationship turns problematic because expresses the general anxiety of non being able to monitor and disciplinize labour.

In fact, its unstructured, extemporaneous nature makes playfulness ideologically incompatible with standardized production of value. Equally incompatible is creative work as the uniqueness associated to subjective use-values frictions with the abstraction capabilities of exchange value, and this why most modding remain unnoticed.

As a result, the "play" aspect of video game testing appears as the underdeveloped, unrealistic, infantile ambition and possibly, by resonating with classic concerns for media effects linked to video games, even degenerative.

As already mentioned, the current capitalist mode is far from disdaining entertainment as a powerful mediator between productive and consumptive practices. Never the less, as I will argue in a moment, the anarchic nature of "Playing for a living" is far less compatible with post fordist ideology than "game for a living. Thus, not surprisingly, blogger Jason Bay considers game testing to be only meant as an entry-level job to allow one video game enthusiast to place "a foot inside the game industry", a "job at for students making their way through college." A dimension that is perceived outside the conventional circuits of higher education degrees. It is also practically relegated to a second class citizen kind of job because it really represents the precariousness and poor working condition of knowledge working: low pay, high hours, high working flexibility, almost always not benefits. Indeed, video game testing echoes the process of proletarization that many knowledge work experience in current circumstances (Fuchs 2010).

Thus, the ludicrous theory of value expressed by video game testing is not simply invisible but rather repressed by ideologically informed judgments that express the incompatibility of playing for living with capitalist labour theory of value. The second dimension of play-working that becomes invisible is linked to the creative performance of "modding". According to Levy and Noval (2009) modding represents a way in which video game testers can marketize their capabilities to manage video game coding, therefore their expertise. In fact, the alteration of the program coding in order to have the video game functioning in a manner different from the original remains in most cases unnoticed.

Modding possibly represents the only positively creative aspect an otherwise wholly negatively conceptualized task. In fact, modding in many ways allow testers to "play-workingly" reimagine and re-invent the game. It is a practice that expresses a vitalist sentiment that goes against the fairly explicit metaphor of social control inherent in the bounded environment of video games. From this point of view, modding is an expression of that creative thrust that distinguishes people from machines and other animals as Marx (1867) notices:

A spider conducts operations that resemble those of a weaver, and a bee puts to shame many an architect in the construction of her cells. But what distinguishes the worst architect from the best of bees is this, that the architect raises his structure in imagination before he erects it in reality. At the end of every labour-process, we get a result that already existed in the imagination of the labourer at its commencement. He not only effects a change of form in the material on which he works, but he also realizes a purpose of his own that gives the law to his modus operandi, and to which he must subordinate his will (174).

From the perceptive of the oppositional relationship between game-labouring and playworking, modding potentially constitutes a subversion of the rule constraining the game 
which entails re-signifying objects situations, adding news ones, deleting others. Canon (2007) shows how modding can re-signify in provocative ways a given video games. She provides the example of Nude Raider as the patch of the late 1990s popular game Tomb Raider, by altering Lara Croft's sexual orientation or the parody of shooter game CastleWolfestein being modified in to the humorous versions of Castle Smurfenstein, in which the Nazi guards are replaced with Smurfs.

Such practices remind the political gestures or appropriation and re-signification associated to the Situationist international movement's subversion of the urban environment rules (Lund 2014) but also Bakhtin's (1965) notion of Carnivalesque. In fact, just like in Carnival, modding suspends or even reverse regulations and social hierarchies i.e. just like the scary Nazi guards of Castle Wolfenstein become Smurfs. Through modding then, the semantic limits of game are tested, the boundaries trespassed and its rules disobeyed.

However, those practices associated to video game testing hardly reach visibility. First of all, that is because most mods do not progress very far and are discarded without ever having a public release. Instead, most frequently they remain relegated as in-group performances in Internet websites such as Gamedev.com and Moddb.com. Second, most of those mods cannot stand alone but rely on the original software, thus becoming object of possible intellectual property right arbitrations or invisible as unpaid labour incorporated in the game without recognition.

When, on the other hand, a given mod gains recognition is frequently commercialized and therefore looses is playful subversive side. For instance, many developers such id Software, Valve Software, Epic Games explicitly exploit the free work of those modding communities to replace video game testers or to generate video game adds-on for free.

\section{Invisible Game-Labour}

Capitalism wise, while play-working appears as mostly dysfunctional, game -labouring is frequently celebrated through icons of capitalist's collective imagery as the stock brokers of Wall Street involved in playing the stock market game. Even more significant expression of game-labouring's elective affinities with capitalism is the link between modern statistics and gambling, a rational calculation of risks that not accidentally remind of bookkeeping and accounting practices of the entrepreneur.

In this sense, the video game industry exemplifies very well the better suitability of gamelabouring as opposed to play-working.

At the same time, in the case of video game testing, game-labouring produces a powerful layer of invisibility that closely reminds of Marx's commodity fetishism (1867). Marx (1867) in Capital identifies the essence of the commodity structure of capitalism in the tendency to make social relations between people appear as relations between things. When a good becomes a commodity, it "changes into a thing which transcends sensuousness" (163). What is, in fact, a social relation between people (between capitalists and exploited labourers) instead assumes "the fantastic form of a relation between things" (165).

If for most jobs, fetishism is considered to be as an unwanted outcome derived by the nature of the commodity form and sophisticated forms of division of labour, in the case of video game testing, the worker succeeds when such fetishism explicitly actualizes and the player can enjoy the fictitious world of the game as a universe with its own life. In fact, the appearance of a video game as a complete and self-sufficient system depends on the fundamental task of getting rid of glitches/bugs because they would reveal the faultiness, the fakeness as well as human errors. As a result, video game testers work immerged in a deep level of fetishism because their labour is to make sure the game is rendered as an environment flawlessly dominated by relation among elements, which id the simulation is accomplished, appear as fetters with their own independent existence.

Thus, as previously mentioned, unless involved in the "subversive" practice of modding, video game testers' task is to erase the very practical reasons that justify their profession. They are like ghostly "prison guards" that check the safety features of such a controlled environment, inhabitants of a negatively defined social ontology that paradoxically enough, draws 
its metaphysics of "presence" from elimination and debugging. Therefore, the more effective they are in the their job more invisible appear their intervention.

Furthermore, video game testers, by refining the formalist qualities of a given game, also superimpose to the (potentially) unique work and use-value originally present in a new game in the form of idiosyncratic coding, errors and defects into something easily abstractable as exchange value. Thus, those quality assurance workers make sure the experience of playing a given game responds to pre-existing criteria such as game enjoyability, game genre, ideologically predominant telos such as winning, succeeding, completing the game.

Summing up, when examined through the analytic categories of play-working and gamelabouring, video game testing productive activity appears as ideologically and practically annihilated, thus sinking its labour into a concealed dimension. In the last section of the paper, I would like to extrapolate what video game testing may reveal about the larger and more general condition of the current capitalist system and knowledge work.

\section{Informational Capitalism and the Knowledge Worker}

In my view, the peculiar tensions between play-working and game-labouring and their implied levels of invisibilities are manifestations of a much larger reality and how the current mode of economic development creates and extracts values from knowledge workers. According to Kerr, "digital games appear to epitomizes an ideal type of global post-industrial neo-liberal cultural product" $(2006,1)$, which originates from the capability of capitalism to link the consumption of commercial entertainment with productive processes. In fact, while in the early 1980 s computer game were intimately connected to local hobby of computer programmers (Swalwell 2012), since then, we have assisted to an increasingly faster process of their commercialization in the contest of the so called digital economy.

Digital economy consists of a transnational articulation of processes of production, consumption, power, and social struggles mediated by networked information and communication technologies and knowledge processes that follows the so called post-fordist paradigm. As Harvey (1989) notices, in response to economic crisis of over-production of mid 1970s, capitalism transitioned from a Fordist mode of development to the Post-Fordist mode of development, which implied a flexible organization production and accumulation, decentralization, and reduction of wages costs. The flexibility Harvey refers describes the formidable capability of Post-Fordism to constantly re-organize itself by changing relations, subjects and localizations at incredible speed.

In such a context, knowledge and information have become increasingly preponderant productive factors so that labour progressively undertakes relational, cognitive, imaginary and sense-making, affective and caring activities (Virno 2004) and the knowledge worker by producing value produces itself by integrating language the mind and creativity in the valorization process (Berardi 2009). Thus the knowledge and relational abilities of the worker and society's "general intellect" become a preponderant resource of the process of valorization (Dyer-Witheford 2005).

As a result, knowledge capitalism should be understood and examined as the intersection of subjective expertise of the knowledge worker as a productive force and the objective dimension of "machines", i.e. information and communication technologies that store, move, reproduce such a knowledge wealth. Indeed, computers and the software industry, including games, become fundamental point of intersection of means of production, circulation, and consumption.

\section{Unsung heroes, un-heard messages and inverted fetishism}

Indeed, the video game tester appears as the knowledge worker operating with networked computers who becomes a "prosumer" (Bruns 2008), a producer and consumer of media commodities. In fact, the video game tester productively consumes video games because by playing acquire the skills, the knowledge that would allow him/her to detect defects. At the same time, the tester consumptively produces when he/she needs to assess the level of entertainment and playability of video game or when he/she produces monetizable modding. 
The video game tester is inserted into this new mode of production that "tends to overcome the separation "between working-time and lifetime, working place and life place, and production and reproduction" (Morini and Fumagalli 2010, 240). The video game tester literally "consumes" those boundaries by vocationally and professionally playing/testing games at home and in the office, when working and when relaxing.

Because of such a capability to live, work, in a permanent condition of liminality (i.e. in between the boundaries of production /consumption/play-working/game-labouring) video game testers are the undetected or unsung heroes of knowledge working. That is because the tendency of their labour to be "fetishized" generally resonates with the invisibility of all that labour involved in creating, reproducing and maintain the media infrastructure that allows media content to circulate. In fact, if on the one hand digital economy aims at bridging "offline and "online" practices together in order to commodify new spheres of our lives, on the other it creates an enormous vacuum between what we see on the screen of our computer and the work necessitated to materially/intellectually produce digital media content: thus video game testing is not so different from the worker mining raw material to build component of media infrastructure content.

It is possibly in this digital realm, apparently removed from concrete material labour, that subjectivities such as video game testers and Facebook or Instagram enthusiasts producing user-generated content become what for Terranova (2013) are "free labourers:" in the twofold sense of being unpaid or underpaid workers and in the sense of being workers that understand their activity as voluntary, vocational and even fulfilling. Thus, according to Terranova, labour becomes invisible concealed under the rhetoric of individual willingness that emphasize the "uses and gratifications" of the Instagram or facebook users.

Therefore, if McLuhan's $(1964,8)$ statement "the medium is the message" still holds in this context, the mediating message of digital labour appears very inconsistently heard and seen. This leads to another paradoxical aspect of digital economy in part revealed by video game testing: the simultaneous presence of both fetishism and inverted fetishism. I have already described the fetishism of video game testers' labour becoming invisible because players cannot see in games relation among people (such as labour and human errors-bugs), but only relations among objects. However, interestingly enough, social media seem to produce fetishism by working in the opposite way: hiding objects behind people.

In fact, a powerful rhetoric celebrating the production of sociability of social media (Arvidsson and Colleoni 2012), their democratic and liberalizing potential (Boyd 2010) is gradually investing video gaming (Kline, Dyer-Witheford and de Peuter 2003; Steinkuehler and Williams (2006) because of the blending of off-line and online environments, video sharing social and networking possibilities of video games.

Behind these spectacular network of players linked by social media remain concealed basic "things" of capitalism: labour, value production, and capital accumulation to the point that according to Andrejevic (2012) social media users are not completely aware of labouring for free and being exploited.

Thus, to conclude, video game testing's invisible labour can be treated as a particular fragment of general reality in which digital capitalism operates by a counterpoint of concealment and exposition of different facets/elements of the process of production of value, media content, subjectivities and social relations.

\section{Conclusion}

In this paper, I have used video game testing as a lens through which exploring significant aspects of digital economy such as the intersection of different kind productive practiceswork and labour-and more or less structured kind of entertainment-play and game, and how they tend to obscure and illuminate different facets of knowledge work.

Those are all characteristic of what Harvey (2005) defines as the flexible accumulation of post-Fordism. As in the case of video game testing, its flexibility implies small productive units organized for specific projects that often exist only for the duration of those particular jobs. As a result of it, those are jobs characterized by "precariousness, hyper-exploitation, 
mobility, and hierarchy" (Lazzarato 1996, 136). Indeed, video game testers respond to the description of Lazzarato provides of "intellectual proletarian" (196), and, as in the case of the proletarian worker, the labour involved in it, becomes hardly noticeable.

In the case of video game testing labour becomes opaque by different dynamics. On the one hand, from the point of view play-working appears as mostly ideologically incompatible with the logic of capital accumulation, which leads to a general depreciation of this job. On the other, from the perspective of game-labouring, testers succeed when the world of codes, objects and simulacra of people of a given video game appears auto-poyetic, self-sufficient, completed, removed from that human imperfection that would cripple the simulation. Consequently, like in a Baudrillean (1994) hyper-real, video game testers succeed when the simulation exceeds real life people and the task of eliminating glitches becomes a fundamental creative work. Unfortunately the price for such a demiurgic capacity is the disappearance of their labour.

To conclude, linked to the tendency of concealing labour exemplified by the study of video game testing, ultimately what is at stake, is not simply its "immateriality" as Lazzarato would say (1996) but rather its de-materialization: its abstraction from concrete labour processes. Thus, when critics such as Fuchs (2010) talk about over-exploitation of knowledge labour, we do not have necessarily to think of updated Charles Dickens's stories of hardship and Victorian slums but rather the danger of unconventional forms of labour and exploitation that can be hardly detected and therefore be hardly antagonized.

\section{References}

Andrejevic, Mark. 2012. Estranged Free Labour. In: Digital Labour: The Internet as Playground and Factory, edited by T. Scholz, 147-164. New York: Routledge.

Arendt, Hannah. 1958. The Human Condition. Chicago, IL: University of Chicago Press.

Arvidsson, Adam and Elanor Colleoni. 2012. Value in informational capitalism and on the Internet. The Information Society: An International Journal 28 (3): 135-150.

Asplund, J. 1987. Det sociala livets elementära former. Göteborg: Korpen.

Bakhtin, Mikhail. 2007. Rabelais and his Worlds. Bloomington, IN: Indiana University Press.

Barbrook, Richard and Andy Cameron. 1996. The Californian Ideology. Science As Culture 6, Part 1 (26): 44-72.

Baudrillard, Jean. 1994. Simulacra and Simulations. Ann Arbor, MI: University of Michigan Press.

Bay, J. 2013. How to Become a Video Game Tester (FAQ). Gameindustryacarrerbuilder. http://www.gameindustrycareerguide.com/how-to-become-a-video-game-tester/. (Accessed November 13 2014)

Boyd, Danah. 2010. Social Network Sites as Networked Publics: Affordances, Dynamics, and Implications. In: Networked Self: Identity, Community, and Culture on Social Network Sites, edited by N. Papacharissi. New York: Routledge.

Briziarelli, Marco. 2014. The Ideological Reproduction: (Social) Working and Labouring in Digital Landscapes. tripleC 12 (2).

Cannon, R. 2007. Meltdown. In: Videogames and Art, edited in Clarke, Andy and Grethe Mitchell. Bristol: Intellect Books.

Croce, Nicholas. 2007. Cool Careers Without a College Degree for People who Love Video Games. New York: Rosen Publishing group.

Dyer-Witheford, Nick and Greig de Peuter. 2009. Games of empire: Global Capitalism and Video Games. Minneapolis: University Of Minnesota Press.

Fuchs, Christian. 2010. Labour in Informational Capitalism and on the Internet. The Information Society 26 (3): 179-196.

Fuchs, Christian and Sebastian Sevignani. 2013. What is Digital Labour? What is Digital Work? What's their Difference? And why do these Questions Matter for Understanding Social Media? tripleC 11 (2): 237-293.

Hardt, Michael and Antonio Negri. 2009. Commonwealth. Cambridge, Mass: Belknap Press Of Harvard University Press.

Kerr, Aphra. 2006. The Business and Culture of Digital Games: Gamework/Gameplay. London: SAGE. 
Kline, Stephen, Nick Dyer-Witheford and Greig de Peuter. 2003. Digital Play: The Interaction of Technology, Culture and Marketing. Montreal: Mcgill-Queen's University Press.

Lazzarato, Maurizio. 1996. Immaterial Labour. In: Radical Thought in Italy: A Potential Politics. Minneapolis: University of Minnesota Press.

Levy, L. and Jeannie Novak. 2010. Game Development Essentials. Game QA and Testing. New York: Delmar.

Lund, Arwid. 2014. Playing, Gaming, Working and Labouring: Framing the Concepts and Relations. tripleC 12 (2): 735-801.

Marx, Karl. 1867. Capital: A Critique of Political Economy. London: Lawrence and Wishart.

McLuhan, Marshall. 1964. Understanding Media: The Extensions of Man. Cambridge MA: MIT Press.

Schultz, Charles P., Robert Bryant and T. Langdell. 2011. Game Testing all in One. Dulles: Mercury Learning and Information.

Steinkuehler, Constance and Dmitri Williams. 2006. Where Everybody Knows Your (Screen) Name: Online Games as 'Third Places'. Journal of Computer-Mediated Communication 11 (4).

Swalwell, Melanie. 2012a. The Early Micro User: Games Writing, Hardware Hacking, and the Will to Mod. In: Proceedings of DiGRA Nordic 2012 Conference: Local and Global-Games in Culture and Society. Tampere: DiGRA. http://www.digra.org/dl/db/12168.37411.pdf.

Sloper, T. 2011. Working as a Tester. Sloperama.com. http://www.sloperama.com/advice/lesson5.htm.

Taylor, Allan and James Robert Parish. 2007. Career Opportunities in the Internet, Video Games and Multimedia. Infobase Publishing.

Thang, Jimmy. 2012. The Tough Life of Games Tester. Ign.com. http://www.ign.com/articles/2012/03/29/the-tough-life-of-a-games-tester.

Terranova, Tiziana. 2013. Free Labour. In Digital labour: The Internet as Playground and Factory, edited by Trebor Scholz, 33-57. New York: Routledge.

Virno, Paolo. 2004. A Grammar of the Multitude. Cambridge, MA: MIT Press.

V.T. 2014. Become a Video Game Tester. VT.

Wark, Mckenzie. 2004. A Hacker Manifesto. Cambridge, MA: Harvard University Press.

Weber, Max. 2009. Protestant Ethic and the Spirit of Capitalism. New York: Norton Critical editions.

\section{About the Author}

\section{Marco Briziarelli}

Marco Briziarelli studies critical approaches to media and communication, especially as these fields intersect with broader issues in political and social theory, intellectual and cultural history. He is particularly interested in media and social movements and media driven conceptualizations of labor. His work has appeared in Communication and Critical/Cultural Studies, Critical Studies in Media Communication, Triple C, Continuum: Journal of Media and Cultural Studies, Journal of Communication Inquiry and Journalism. He is the author and coauthor of the books The Red Brigades and the Discourse of Violence: Revolution and Restoration, Reviving Gramsci: Crisis, Communication and Social Change. 